\title{
Recompondo corpos, reconstruindo trajetórias: ações da medicina e da justiça frente à mutilação sexual de meninos*
}

Paula Lacerda**

\section{Resumo}

Entre 1989 e 1993, na cidade de Altamira (PA), 26 crianças desapareceram, foram assassinadas, sequestradas e/ou mutiladas na genitália. Esse caso, conhecido como o "caso dos meninos emasculados" suscitou grande repercussão nas mídias nacional $e$ internacional. Certas características desses crimes contribuíram para sua representação de evento único, diferente de outros casos de violência contra crianças que ocorrem no Pará e em outras partes do Brasil. O artigo busca analisar a centralidade da lesão corporal que foi classificada como "emasculação" na própria repercussão dos crimes, nas ações da medicina e nas propostas de "reparação" à violência sofrida.

Palavras-chave: Sexualidade, Infância, Medicina, Justiça e Direitos Humanos.

\footnotetext{
* Recebido para publicação em 16 de outubro de 2012, aceito em 7 de novembro de 2014.

** Professora de Antropologia da Universidade do Estado do Rio de Janeiro, Rio de Janeiro, Brasil.
} 
300 Recompondo corpos, reconstruindo trajetórias

Recovering Bodies, Rewriting Paths: Medicine and Justice Actions Towards Sexually Mutilated Boys

\begin{abstract}
Between 1989 and 1993, in the city of Altamira, State of Pará, 26 children were murdered, kidnapped and sexually mutilated. Some of the victims disappeared. This case, known as the 'case of the emasculated boys', provoked great interest amongst the national and international media. The characteristics of these crimes contribute to the representation of the event as something unique, different from other cases of violence involving children that took place in Pará, Brazil and other parts of the world. This paper will analyze the centrality of "emasculation" in the crimes, in medicine's actions and in the reparations proposals to the violence suffered.
\end{abstract}

Key Words: Sexuality, Childhood, Medicine, Justice and Human Rights. 


\section{Introdução}

Em novembro de 1989, Pedro $^{1}$, de dez anos, foi abordado por um desconhecido que o convidou para colher mangas nas matas de Altamira, onde vivia com seus pais e quatro irmãos. Ao entrarem na floresta, o menino foi sedado por uma substância de cheiro forte e desmaiou. Pouco depois, foi violentado sexualmente e teve seu pênis e bolsa escrotal extirpados. Algumas horas depois, acordou, percebeu-se ensanguentado e, embora fraco, conseguiu correr e pedir ajuda. Pedro foi socorrido por um leiteiro. Os pais da vítima levaram-na inicialmente à delegacia e de lá foram encaminhados, na única viatura policial existente, até um dos poucos hospitais da cidade.

Altamira localiza-se no sudoeste do Pará e, com 161.445,9 $\mathrm{km}^{2}$, é a cidade o maior município do Brasil, cerca de quatro vezes maior do que o estado do Rio de Janeiro. Altamira foi oficialmente fundada em 1911, mas, antes mesmo dessa, data missões de jesuítas haviam se instalado na região levando consigo serviços básicos de saúde e educação. Como uma "frente de expansão" (Velho, 1981), a região sofreu intervenção das grandes obras de infraestrutura planejadas pelos governos militares na década de 70. Acompanhando os investimentos estatais em hidroelétricas, estradas e portos, milhares de migrantes deslocaram-se para a região, atraídos pela promessa de emprego, terra e melhores condições de vida. Segundo dados do IBGE, em 1960, 11.978 pessoas residiam em Altamira, número que dez anos

\footnotetext{
1 Os nomes das vítimas sobreviventes são fictícios e aparecerão sempre em itálico. Apesar de os casos fazerem parte de um processo judicial que nunca correu em segredo de justiça, assumi o compromisso com os familiares das vítimas de preservar a identidade dos sobreviventes. Da mesma maneira, optei por não identificar o processo judicial em análise. Os demais nomes, inclusive das vítimas que não sobreviveram, são todos reais. Nesse caso, a opção foi por dar visibilidade à "luta" dos ativistas que promovem esforços consideráveis para que os crimes não "caiam no esquecimento". Além dessa convenção, faço uso de aspas duplas para ressaltar termos êmicos, tenham sido proferidas por médicos, juristas ou pelos familiares das vítimas. Uso ainda itálico para palavras em língua estrangeira e ênfases que desejo conferir a certas categorias e expressões.
} 
mais tarde seria de 15.428 e, apenas um ano depois saltou para 23.211 (Cardoso e Muller, 1977:115). Até a "explosão populacional", Altamira era povoada majoritariamente pelos mais de dez grupos indígenas que vivem no local, pequenos comerciantes, agricultores de subsistência e também latifundiários.

Ao intenso fluxo migratório na região, promovido por ações governamentais no bojo da chamada "colonização dirigida" ou mesmo como resultado da iniciativa dos próprios migrantes - a "migração espontânea" (Seyferth, 1990; Tavares, 1972) -, não corresponderam investimentos na saúde, educação, saneamento $e$ assistência social. A ausência de dados oficiais sobre o crescimento da violência na região pode ser parcialmente superada pelos dados apresentados por Almeida (1993) sobre a violência no campo, segundo os quais o Pará estaria no ranking dos estados com maior número de conflitos e mortes durante as décadas de 80 e 90 .

Em 1989, quando Pedro foi encontrado pelo leiteiro, havia uma única delegacia em Altamira. ${ }^{2}$ A I Divisão de Polícia do Interior $^{3}$ registrava boletins de ocorrência, patrulhava $e$ supervisionava casos em uma área equivalente à da França em extensão territorial. Havia poucos hospitais na cidade e a

\footnotetext{
2 Ainda hoje, a cidade conta com uma única delegacia. Apesar de ter mudado suas instalações para um local mais adequado às atividades, a estrutura policial parece ser ainda insuficiente, como pude observar durante o trabalho de campo nas dependências policiais. Ressalto, contudo, a existência de uma Delegacia Especializada de Atendimento à Mulher, em grande parte resultado das reivindicações do Movimento de Mulheres Trabalhadoras de Altamira do Campo e da Cidade, de grande expressividade na região.
}

3 Até 2012, o Sistema de Segurança Pública do Estado do Pará estava organizado a partir de dez diretorias. Uma delas era a Divisão de Polícia do Interior, que tinha a atribuição de dirigir, coordenar, controlar e supervisionar administrativamente dez Superintendências Regionais da Polícia Civil e todas as delegacias do interior do Pará. Com a recente reforma no Sistema de Segurança Pública e Defesa Social, bastante inspirada nos moldes do Rio de Janeiro, a Divisão de Polícia do Interior foi substituída pela Coordenação de Núcleos Regionais. A Gerência de Altamira é um dos sete existentes. Para organograma da Secretaria de Estado de Segurança Pública e Defesa Social ver: [www.segup.pa.gov.br/]. 
assistência social era prestada através de iniciativas da Igreja Católica. Devido à carência de condições médicas em Altamira, após um primeiro atendimento Pedro foi levado a Belém e submetido a diversas cirurgias, das quais trataremos adiante.

Dez meses depois desse crime, João, de nove anos, foi abordado por um sujeito que o levou para a mata, sob a promessa de pegar uma pipa engatada na árvore. Da mesma maneira que Pedro, João foi sedado. Antes que desmaiasse, a vítima escutou algumas vozes $e$ viu, por baixo do pano que vendava seus olhos, pernas de várias pessoas que o circundavam. Ao acordar dias depois de ter sido visto pela última vez, gravemente ferido, João foi acolhido por uma senhora que o levou para a beira da estrada, em busca de socorro. João foi vítima de violência sexual e teve o pênis extirpado com a preservação dos testículos.

Cinco outros crimes ocorreram até que Jaenes da Silva Pessoa, de 13 anos, fosse sequestrado enquanto pastoreava o gado de seu pai nas terras de familiares. Jaenes desapareceu às vésperas das eleições municipais de 1992 e, diferente de Pedro e João, não sobreviveu. Na contagem do ativismo que se formou a partir dos casos - composto por lideranças do Movimento de Mulheres e da Igreja Católica às quais, posteriormente, se uniram os familiares das vítimas -, Jaenes era a segunda vítima letal do "caso" e a sexta "emasculada". O desconhecimento da identidade do criminoso, a impossibilidade de compreender o porquê dos crimes, o sequenciamento das vítimas, as características desumanas e a aparente inação das "autoridades" construíam a sensação de terror da população. ${ }^{4}$ Conforme argumenta Araújo

\footnotetext{
4 Durante o trabalho de campo, ao comentar com pessoas de Altamira o objeto da pesquisa, muitas foram as que tinham histórias para contar. Algumas diziam terem conhecido pessoalmente alguma vítima ou acusado, outras afirmavam acreditar que vários outros "poderosos" estavam envolvidos nos crimes apesar de jamais terem sido oficialmente investigados. Rapazes na faixa dos 30 anos contavam suas experiências pessoais de medo de qualquer estranho que se aproximasse na época dos crimes e do alívio que sentiram na ocasião da prisão do primeiro dos acusados. Tais relatos indicam que o "caso" foi incorporado às biografias de mais pessoas do que aquelas diretamente implicadas e que essas
} 
(2012:224), formas extremas de matar e de inscrever a dor nos corpos são parte de uma política do medo que produz controle social.

O medo de Dona Rosa Pessoa, mãe da vítima, com o que pudesse ter acontecido com seu filho logo que foi dada a notícia do desaparecimento resultou na imediata organização de um mutirão de buscas. Enquanto a mãe organizava o mutirão, o pai, acompanhado por um parente advogado, foi à delegacia registrar o desaparecimento e solicitar que buscas fossem feitas, mas não teve sucesso na demanda. O policial de plantão informou que a viatura estava ocupada com a segurança das urnas da eleição. Até o encontro do corpo, nenhum registro fora efetuado. ${ }^{5}$

Apesar de os pais acharem que Jaenes poderia estar ainda vivo quando se deram conta do sumiço do menino, eles não poderiam fazer outra coisa além de percorrer locais ermos em busca do corpo. Outro efeito do "terror" sobre as pessoas é a produção de não ditos, a proliferação de "rumores", como indica Das (2007). Em Altamira, era através de "rumores" que circulavam nomes de possíveis envolvidos e falava-se que as vítimas eram apenas sedadas na mata, para depois serem levadas a chácaras e sítios distantes, onde os crimes eram praticados. Os corpos, já sem vida, eram deixados na mata. Nesse sentido, os familiares consideravam que enquanto faziam buscas pela mata, seus meninos estavam sendo torturados $e$ assassinados em

experiências são também narradas em termos de medos e traumas, mas não como dor e sofrimento.

5 Em todos os casos de desaparecimento de crianças em Altamira, a polícia local recusou-se a fazer um boletim de ocorrência antes de 48 horas do sumiço. Tal medida, referida como uma "norma" da polícia, não possui respaldo na legislação brasileira. A prática das " 48 horas", no entanto, é a tal ponto generalizada que em dezembro de 2005, foi sancionada a Lei federal $\mathrm{n}^{\circ}$ $11.259 / 2003$ conhecida como lei da "busca imediata", determinando que "A investigação do desaparecimento de crianças ou adolescentes será realizada imediatamente após notificação aos órgãos competentes, que deverão comunicar o fato aos portos, aeroportos, Polícia Rodoviária e companhias de transporte interestaduais e internacionais, fornecendo-lhes todos os dados necessários à identificação do desaparecido". 
propriedades privadas, protegidas por cercas, vigias $e$, de certo modo, pela omissão da polícia.

Dois dias depois do desaparecimento, o mutirão organizado por Dona Rosa encontrou o corpo de Jaenes. Ele estava com as vestes limpas, sem os globos oculares, o pulso cortado e a genitália extirpada. O velório da vítima, ocorrido em um dia de eleições, teve bastante repercussão. Como o pai da vítima deixaria registrado em seu depoimento à polícia, a certa altura do velório, o cadáver de seu filho começou a sangrar, o que teria sido visto $e$ comentado por todos os presentes. Acreditava-se que um cadáver sangrava quando o assassino estava por perto. Entre os presentes, parentes e amigos da família, colegas e professores da vítima, curiosos, o prefeito então em exercício e vários candidatos locais. Até mesmo o vice-governador do Pará estava presente e teria afirmado ao pai da vítima que falaria pessoalmente com o governador para que uma "comissão" fosse formada e enviada a Altamira para investigar "aqueles crimes". De fato, em duas semanas uma equipe da Polícia Civil chegou à cidade com a missão exclusiva de "desvendar os crimes de emasculação".

Atentos ao desenrolar dos crimes, os religiosos católicos inspirados pela Teologia da Libertação $e$ as mulheres ligadas ao Movimento de Mulheres observaram que as "emasculações" seguiam um mesmo perfil: meninos de oito a 14 anos eram atraídos por um desconhecido sob a promessa de um trabalho, uma brincadeira, uma guloseima. Eram levados a locais ermos onde eram sedados e lesionados em diversas partes do corpo, inclusive na genitália. As vítimas tinham em comum a origem social bastante humilde, além de circularem sozinhas pela cidade, muitas vezes em busca de pequenas atividades remuneradas como vender salgados, engraxar sapatos, lidar com o gado. Algumas das vítimas trabalhavam e estudavam, outras estavam fora da escola. As investigações policiais iniciadas com a morte de Jaenes chegaram a conclusões bastante próximas às do ativismo local.

Para o delegado, a extirpação do órgão sexual das vítimas era a "assinatura" do criminoso. Segundo suas investigações, uma única pessoa estaria por trás de todos os sete crimes, dos quais 
quatro tratavam-se de homicídios qualificados e três eram lesões corporais com tentativa de homicídio. A presença desse tipo de lesão no corpo (vivo ou morto) das vítimas era o que distinguia a violência excepcional - que justificava a presença de uma comissão da Polícia Civil de Belém naquela cidade interiorana da violência cotidiana, como desaparecimentos, sequestros, violência sexual, trabalho infantil. De fato, os crimes alcançaram repercussão nacional $e$ internacional pela combinação de elementos tais como o sequenciamento e a faixa etária das vítimas e, certamente o de maior peso simbólico, a extirpação dos órgãos sexuais. Entendida ora como expressão máxima do sadismo do criminoso, ora como indício de ritual de magia negra, a "emasculação" esteve sempre no centro das atenções a respeito do "caso".

Acompanhando a primeira dessas interpretações, Amailton Madeira Gomes, de 25 anos, filho de um importante comerciante local, foi o primeiro acusado. O jovem, parente não distante da vítima Jaenes, tinha fama de ser "homossexual" $e$ "assediar rapazes", especialmente os militares do exército que serviam no Batalhão de Infantaria na Selva. Para o delegado que comandava o Inquérito Policial, os depoimentos de pessoas que conviveram com Amailton haviam deixado patenteado que "o suspeito dos hediondos crimes é homossexual, viciado em drogas, pervertido sexualmente e o que lhe desperta mais prazer é o ato da prática da felação" (Processo, fls. 186).

No Inquérito Policial que dá origem ao Processo Judicial, a homossexualidade de Amailton tem peso decisivo em seu indiciamento, ocupando maior destaque nos registros do que os indícios que sugeririam a participação no crime. A suposta homossexualidade funciona como um ingrediente central na tipificação de sua personalidade, tornando-o provável vitimador de meninos. Tais associações nos lembram as proposições de Foucault (1999) acerca do "personagem homossexual" que surge no século XIX. Nas palavras do autor, "nada daquilo que ele é, no fim das contas, escapa à sua sexualidade. Ela está presente nele 
todo: subjacente a todas as suas condutas, já que ela é o princípio insidioso e infinitamente ativo das mesmas" (Foucault, 1999:43).

Mais tarde, com o comando das investigações a cargo da Polícia Federal, surgem outros suspeitos. Dois médicos, dois expoliciais militares e uma senhora de nome Valentina Andrade são incluídos como réus no processo. De acordo com o "aditamento à denúncia", o representante do Ministério Público entende que os dois médicos seriam os responsáveis por executar cirurgicamente as mutilações sexuais, já que os contornos das lesões teriam "bordas regulares", atestando terem sido praticados por alguém com habilidade cirúrgica. Os dois ex-policiais militares teriam a responsabilidade de garantir que o local onde os crimes eram praticados estaria protegido e/ou atrair as vítimas para locais ermos. A última das rés, Valentina Andrade, anos antes foi investigada pela polícia paranaense em crimes avaliados como semelhantes ${ }^{6}$ e seria a líder da uma "seita satânica" em cujos rituais os meninos seriam mortos em "oferenda ao "Deus das Trevas'” (Processo judicial, fls. 423).

Essa interpretação, resultado das investigações da Polícia Federal e reforçada pelo Ministério Público, deixa entrever que a "perversidade" que era então derivada de uma sexualidade tida como desviante (a de Amailton, o primeiro indiciado, como vimos acima) passa a ser então associada à prática de "rituais satânicos".

${ }^{6}$ Em 1992, Leandro Bossi, de sete anos, desapareceu na cidade de Guaratuba, balneário paranaense. Dois meses depois, na mesma cidade, desapareceu Evandro Caetano, de seis anos. Diferente de Leandro, que nunca foi encontrado, o corpo de Evandro foi encontrado "com as mãos amputadas, escalpelado, com os dedos dos pés cortados, sem os olhos, sem as orelhas, sem o osso externo do tórax" (Cf. Caetano, 2010:5). Nos dois casos, Valentina Andrade, que estava hospedada em uma pousada na cidade, foi investigada pela polícia que apresentou como indícios capas e capuzes que seriam utilizados em "rituais de magia negra". Esses crimes foram objeto de uma matéria na revista Veja sob o título "Suspeita Diabólica" (28/07/1992) que foi o que levou os policiais federais que atuaram em Altamira a suspeitar que Valentina - que, de fato, tinha estado em Altamira por duas vezes antes de os crimes de emasculação ocorrerem tivesse envolvimento com os crimes ali praticados. A respeito dos crimes do Paraná, Valentina Andrade não chegou a ser envolvida no processo judicial. 
O "concurso de agentes", isto é, a reunião de várias pessoas para a prática de um mesmo crime, seria explicado por serem eles participantes de uma mesma "seita" que faria "rituais" com o propósito de fornecer poder, vigor físico e potência sexual a seus beneficiários (pessoas "poderosas", "influentes" e "ricas"). As crianças seriam vítimas nos crimes por serem "inocentes" e o órgão sexual seria a "oferta", por isso extirpado dos corpos e jamais encontrado. Como algumas vítimas tiveram os pulsos e pescoços cortados, acreditava-se que o sangue possuía também alguma função no ritual, talvez sendo consumido pelos participantes.

Apesar da falta de provas sobre a relação entre os crimes e o "ritual satânico", foi essa a explicação apresentada aos jurados durante o julgamento do único processo existente. Na ocasião, a promotora de justiça pediu a condenação de todos os acusados, obtendo êxito em quatro dos cinco casos (um dos acusados, foragido há anos, foi dado como morto). Contudo, justamente a ré que seria a líder da seita, conforme acusação do Ministério Público, foi inocentada pelo tribunal do júri. Após ter sido lida a sentença absolutória da ré, a representante do Ministério Público na acusação teria declarado à imprensa que iria "rasgar a sua beca e sepultar a justiça em praça pública", pois a decisão dos jurados contradizia inúmeras provas incluídas nos autos. Efetivamente, Valentina Andrade foi absolvida desse processo e, alguns anos depois, deu entrada com uma petição na Organização dos Estados Americanos (OEA) demandando indenização por danos morais e humilhação. ${ }^{7}$

Traçado esse panorama geral do "caso dos meninos emasculados", o objetivo deste artigo é discutir as medidas reparativas promovidas pela medicina e pela justiça em relação ao

\footnotetext{
7 "Vidente denuncia o Brasil na OEA - INDENIZAÇÃO: Valentina alega que foi vítima de violações dos direitos humanos", Portal ORM, 12/05/2009.
} 
"caso", às vítimas e a seus familiares. Argumento que a "emasculação" ocupa um lugar central em ambas, embora de modos distintos. Na visão dos médicos, a reconstrução do órgão sexual seria o primeiro e mais importante passo para reconstrução da vida dos sobreviventes. Para os operadores do direito que traçaram os contornos do que seria o "caso" na justiça, a "emasculação" se configura como quesito fundamental, o que confronta o movimento social formado pelos familiares das vítimas. Enquanto, na visão do grupo, 26 meninos teriam sido vítimas do "caso", a polícia denunciou à justiça oito crimes, dos quais três ficaram de fora do julgamento. Treze anos depois, o governo do Pará, na gestão de Simão Jatene (PSDB), concedeu pensão especial e vitalícia aos sobreviventes João e Pedro, o que será também analisado como parte do processo mais amplo de "reparação" aos crimes, seguindo os dispositivos estipulados pela Comissão Interamericana de Direitos Humanos.

Eleger as "emasculações" como foco da análise permite perceber, como busco demonstrar, o caminho seguido por médicos, ativistas, políticos e agentes da administração pública visando minimizar os efeitos da violência na trajetória das vítimas e de seus familiares. Veremos como, a despeito de outras formas de violência praticadas, é em torno da mutilação sexual que as medidas reparativas são construídas e aplicadas.

$\mathrm{O}$ artigo está dividido em duas partes. Na primeira delas, discuto as ações da medicina a partir dos entendimentos sobre corpos e identidades, passando pela dupla sexo-gênero. $\mathrm{O}$ pressuposto de que a reconstrução do órgão sexual seria o mais importante passo para recuperação daquelas vidas aponta para a centralidade do corpo na construção de identidades, pertencimentos e subjetividades, conforme demonstrado por várias pesquisas no campo das ciências sociais, dentre as quais destaco Laqueur (1990), Fausto-Sterling (2000) e Machado (2005), com as quais buscarei dialogar. $\mathrm{O}$ argumento de Laqueur, reforçado pelas autoras, é que não apenas o gênero, mas também o sexo é socialmente construído e fruto de relações de poder. $\mathrm{O}$ predomínio do binarismo sexual produz o temor pela 
ambiguidade (Douglas, 1976) e restringe a variedade a um único modelo.

$\mathrm{Na}$ segunda parte do artigo, discuto a resposta do Estado aos crimes, no plano jurídico e no âmbito do direito civil, no que se refere à concessão de indenização aos sobreviventes $e$ aos familiares das vítimas mortas e/ou desaparecidas. Analiso o sentimento de "justiça" perseguido pelos familiares das vítimas, inicialmente concentrado na demanda pelo julgamento e, depois de tal feito, na concessão de indenizações. Apesar de a mobilização em torno do "caso" considerar como vítimas não apenas os meninos sexualmente mutilados, as ações em torno do julgamento e das pensões privilegiam essa dimensão sobre todas as demais. Buscando perceber o que as indenizações podem reparar, argumento que a noção de sofrimento comparece como marca da trajetória dos meninos sobreviventes e também dos familiares das vítimas que dedicaram suas vidas à "luta" em nome de seus filhos e irmão. ${ }^{8}$

As perspectivas finais discutem dois últimos aspectos acerca das "emasculações", relativos aos acusados e à "luta" dos familiares das vítimas. O material empírico que embasa este artigo é composto por matérias publicadas em periódicos paraenses, pelo processo judicial, pelo relatório da assistência social acessado a partir do Centro de Defesa da Criança e do Adolescente (CEDECA-Emaús) e por entrevistas realizadas com agentes envolvidos no "caso", como delegado, advogados, juízes, promotores e familiares das vítimas que formaram o Comitê em Defesa da Vida da Criança Altamirense (doravante, Comitê), bem como seus apoiadores. Sobreviventes e acusados, por motivações distintas, não foram acessados durante a pesquisa.

8 O termo "luta", conforme Comerford (1999), faz parte da gramática que dimensiona o empenho das pessoas na mobilização social, embora, como mostra o autor, a categoria também tenha seu uso atrelado às situações da vida cotidiana. No sentido explorado por Weber (1974:31), "luta" é a ação social que se orienta pelo propósito de impor a própria vontade contra a resistência proveniente de outras partes. Sigo, neste texto, o sentido proposto pelos dois autores. 


\section{Recompondo corpos}

A partir do campo das ciências sociais vem sendo questionada, há algumas décadas, a ideia de que a medicina e suas especialidades simplesmente buscam restabelecer um modelo de "normalidade" afetado seja pela doença, má formação congênita, traços hereditários ou acidentes. Autores como Latour e Woolgar (1997) apontam para a dimensão cultural implicada em todas as áreas do conhecimento, inclusive naquelas tidas como mais "duramente científicas", que manipulam substâncias em laboratório. O relativo apartamento entre os "fatos científicos" e o percurso por meio do qual eles foram construídos seria, como argumentam os autores, uma forma de obscurecer algo decisivo na produção das "descobertas": as negociações entre pesquisadores e a construção de estratégias de persuasão $e$ convencimento.

Se todo o conhecimento produzido é um conhecimento cultural, a anatomia humana deve ser percebida como produto das relações sociais e, como tal, das relações de poder. Ao apresentar um modelo de percepção dos corpos femininos $e$ masculinos que não se baseava na "diferença", mas na "hierarquia", Laqueur (1990) demonstra muito claramente a contextualidade de nossas percepções sobre a "natureza" dos corpos. Segundo o autor, o modelo de dois sexos teria surgido durante o século XVIII, quando se abandona a percepção grega de que a completude dos corpos seria resultado do calor responsável por fazer os órgãos sexuais "externalizarem-se". Os corpos femininos, nessa visão, seriam inferiores aos masculinos, posto que "incompletos".

A crença no dimorfismo sexual como modelo "natural" dos corpos, no campo da clínica médica, fundamenta as cirurgias de pessoas nascidas com a chamada "genitália ambígua", como discutidas por Machado (2005) e, no campo da política sexual, produz a rejeição ou o estranhamento de experiências corporais que fujam a esse modelo, como as intervenções corporais em travestis e transexuais. As divisões sexuais se impõem com tal 
força sobre as representações sociais de corpos, saúde e padrões de normalidade que os que se afastam desse modelo são controlados, medicalizados e punidos. Contudo, como lembra Fausto-Sterling (2000:15), "rotular alguém como homem ou mulher é uma decisão social".

Conforme argumento, a equipe médica responsável pelo atendimento dos sobreviventes às "emasculações" esforçaram-se para que aqueles corpos não permanecessem como "aberrações" (Foucault, 2002), no caso, como um corpo indefinido, um corpo masculino sem o elemento que o define: o órgão sexual. Evidentemente, não defendo que cirurgias reparadoras não devessem ter sido realizadas nos corpos das vítimas, até porque elas mesmas, em entrevistas à imprensa, referem-se às cirurgias como sendo "seu maior desejo". O que busco analisar é a percepção da dimensão estética do corpo como suporte para o gênero e para a sexualidade, bem como suas implicações.

Quando Pedro foi levado a Belém em busca de atendimento médico, foi recebido pelo urologista e cirurgião Dr. Lourival Barbalho, professor universitário e profissional de renome. O médico atendeu o menino ainda envolto pela tabatinga, um tipo de lama característica dos solos argilosos da Amazônia que, por suas propriedades cicatrizantes, acabou por salvar-lhe a vida. No consultório médico, a situação de Pedro foi classificada como sendo um "caso de emasculação total", que para o médico queria dizer "perda dos órgãos genitais externos e gônada, inutilização das funções sexual e reprodutora e debilidade da função da micção", como posteriormente deixou registrado no parecer solicitado pela justiça (Processo, fls. 3748).

No centro cirúrgico, o primeiro procedimento do médico e de sua equipe foi desviar o canal da uretra para a base da pélvis, para que a vítima pudesse urinar. Essa seria apenas a primeira cirurgia. O tratamento, tal como estimado pelo médico, seria longo, custoso e doloroso, mas necessário para que a vítima pudesse recompor sua vida. Para o médico, a extirpação do pênis poderia ser mitigada com o uso de próteses ("Psicopata desafia a polícia". O Liberal, 12/09/93). Apesar da recomendação expressa de 
que o tratamento não fosse interrompido, após a primeira intervenção cirúrgica o menino foi mandado de volta à sua cidade onde ficou sem acompanhamento médico e sem possibilidade financeira de deslocar-se para a capital.

O modelo de tratamento planejado pelo Dr. Barbalho ressaltava a importância de atendimento psicológico e da assistência social à vítima e a seus familiares, o que era prestado de modo assistemático pela prefeitura de Altamira. No caso de João, os primeiros socorros foram prestados em Altamira, mas logo depois ele foi também levado para ser atendido pelo Dr. Barbalho. Da mesma maneira, o canal da uretra foi desviado para a base do pênis, "possibilitando a micção" $e$ "diminuindo as chances de infecções".

Passado o momento de grande repercussão das mutilações de Pedro e João, as vítimas ficaram sem acompanhamento médico e psicológico. Em relação aos crimes em si, a polícia sequer abrira inquéritos policiais. Ao longo de todos esses anos, o tratamento dos sobreviventes avançava um novo passo em duas situações possíveis: com o andamento das investigações do "caso" na polícia e na justiça e com a divulgação do "drama" de João e Pedro na imprensa. Em ambas as situações, portanto, a retomada dos atendimentos médico, psicológico e social aos sobreviventes não se dava sem exposição pública de suas vidas. Nesse sentido, a reportagem "Os sobreviventes foram abandonados", publicada pelo jornal O Liberal em meados de 1993, antecedeu o início do tratamento hormonal nas vítimas. Entre outras coisas, a matéria denuncia que com a entrada na puberdade, Pedro, que teve também os testículos extirpados, estava desenvolvendo caracteres secundários femininos, como voz fina e mamas.

O reinício do tratamento médico se deu oito anos depois do crime contra a primeira das vítimas, com a cirurgia de "falodermatoplastia", ou seja, a reconstrução plástica do pênis. Nesse momento, entra em cena o cirurgião plástico Dr. Bragança, que alcançara fama ao operar um jovem de 23 anos que havia nascido sem o pênis (agenesia congênita). Apesar da prótese disponibilizada pelo governo ter sido avaliada como de qualidade 
inferior à importada que foi solicitada pelo médico, as cirurgias foram feitas. Em dezembro de 1997, o Dr. Bragança assim descreveu o processo cirúrgico em curso:

No primeiro momento da operação, foi feito um duto a partir de um enxerto de pele obtido do próprio abdômen dos meninos. Seria como se estivesse nascendo um pênis com duas bases no corpo deles. Na segunda fase da cirurgia, a extremidade superior do tubo foi separada do abdômen. Logo em seguida, foi aberto o coto residual do pênis, expondo os corpos cavernosos interpélvicos. Antes de proceder à sutura da extremidade superior, foi colocada uma prótese em forma de Y. Depois, as duas hastes menores foram introduzidas nos corpos cavernosos $e$ a haste maior, no pedículo cutâneo. No terceiro tempo desse processo cirúrgico, a extremidade inferior do enxerto tubular foi cortada e finalmente separada da parte abdominal, o que fez os garotos terem novamente um pênis ("Cirurgias podem devolver vida sexual aos meninos de Altamira" A Província do Pará. Caderno Cidades, Belém, 15/12/97).

A segmentação das cirurgias em diferentes etapas visava evitar rejeições da prótese. Além disso, esperava-se que concomitantemente a elas fosse realizado o acompanhamento psicológico das vítimas para que elas pudessem melhor suportar o processo de intervenção corporal. Para a psicóloga:

Os espaços de tempo entre uma cirurgia e outra não ocorrem à toa. Pelo contrário, são planejados para que os jovens recuperem a parte psicológica. A pressa pode trazer traumas. O período entre as etapas da cirurgia serve para eles assimilarem emocionalmente o que está acontecendo ("Cirurgias podem devolver vida sexual aos meninos de Altamira" A Província do Pará. Caderno Cidades, Belém, 15/12/97).

O pioneirismo da cirurgia a ser realizada em Belém era tema de comemoração. $\mathrm{O}$ tom de otimismo marca o título da matéria "Cirurgias podem devolver vida sexual aos meninos de Altamira" 
e o subtítulo "Os médicos Lourival Barbalho e Carlos Bragança utilizam modernas técnicas cirúrgicas para reconstituir o saco escrotal e pênis de duas vítimas de emasculação". Nas palavras da equipe médica, no entanto, as cirurgias eram percebidas de modo contraditório. Por um lado, o Dr. Barbalho afirmava que: "a cirurgia é meramente estética e servirá apenas para ajudar as vítimas a encontrar a identidade masculina". Por outro, para o Dr. Bragança, após o final das etapas cirúrgicas: "os garotos vão ter realizado o sonho de se tornarem homem, em todos os sentidos da palavra".

A declaração do primeiro médico deixa claro que o caráter estético das cirurgias viria facilitar a busca por uma identidade masculina. Explicitamente, o médico considera que os sobreviventes não teriam ainda uma identidade masculina, mas teriam que buscá-la, e a prótese seria uma ajuda. Na pesquisa de Machado (2005) sobre as representações corporais e práticas sociais de profissionais e de familiares de pessoas classificadas como "intersex", o nível anatômico emerge como elemento primordial na decisão médica de construção desse ou daquele sexo. As decisões são tomadas, como revela a autora, menos em função de uma "facilidade técnica" - que supostamente moveria os médicos a construírem vaginas e não pênis - e mais em função de "restaurar uma natureza incompleta" (Machado, 2005:280) presente em outras partes do corpo que não na genitália "ambígua". Segundo a autora:

É aceito que o [sexo] está impresso em variados locais no corpo humano e que é justamente isso que faz com que diferentes critérios sejam considerados no processo de tomada de decisões quando se está em frente a um caso de intersexo. No entanto, pode-se dizer que um dos níveis, o anatômico, é eleito como fundamental exatamente porque é aquele considerado capaz de remeter ao "sexo verdadeiro" através da genitália construída (Machado, 2005:266). 
No caso dos sobreviventes às emasculações, não havia uma natureza a ser descoberta, como no trabalho de Machado (2005), já que as vítimas possuíam uma identidade de gênero definida quando sofreram a mutilação sexual. Contudo, ainda assim, as ações $e$ as interpretações sustentadas pelos dois médicos que protagonizaram $\mathrm{o}$ atendimento às vítimas revelam percepções acerca de corpos, sexualidades, identidades e sofrimentos. Como veremos adiante, por mais sofrimento que pudessem causar as intervenções cirúrgicas, elas representavam a possibilidade de recuperar uma "identidade", no caso, a masculina.

Nesse sentido, a declaração do segundo médico mostra-se mais otimista que a do primeiro. Para ele, existem muitos sentidos na expressão "homem" e as vítimas, depois da cirurgia, poderiam "desfrutar de todas elas". Ao que parece, o médico se refere a aspectos tidos como fisiológicos (a possibilidade de urinar em pé, a ereção, a ejaculação) e comportamentais, aproximando-se então da "identidade masculina" à qual se referiu o Dr. Barbalho. Sete anos depois dessa última cirurgia, Pedro declararia à imprensa que o pênis implantado representava um mero "acessório" em seu corpo, contrariando até mesmo as previsões do médico menos otimista ("Vítima de emasculação quebra o silêncio". O Liberal, 22/2/04). Nessa reportagem, realizada após do julgamento, a vítima, então com 24 anos, afirma que "justiça" para ele seria a garantia de um tratamento contínuo e a implantação de uma prótese definitiva.

A primeira intervenção médica, como vimos, buscou adaptar a fisiologia das vítimas ao corpo mutilado, de modo que tal cirurgia emergencial desviou o canal da uretra para a base da pélvis. As cirurgias subsequentes, por sua vez, implantaram uma prótese, mas não refizeram a ligação da uretra. As vítimas continuaram a urinar sentadas, o que parecia ser o maior problema enfrentado, ao menos naquele momento de suas vidas. Desde a violência sofrida, João não voltou a estudar, devido à vergonha de urinar sentado no banheiro da escola. Enquanto os médicos tinham no horizonte mais otimista a possibilidade de uma 
vida sexual "normal", as vítimas tinham outra preocupação, que talvez fosse até mais fácil de ser resolvida.

Após complicações no pós-operatório, João foi submetido a uma outra cirurgia para retirada da prótese que o corpo rejeitara, dessa vez, em São Paulo. Conforme o relato da assistente social que acompanhava a vítima e sua mãe, a nova equipe médica considerava que a reconstrução do pênis permitiria ao sobrevivente levar uma vida "normal". Nesse caso, porém, "vida normal" significava estar livre do constrangimento da micção em público, já que "a cirurgia não ultrapassaria os fins estéticos" (Relatório Bio-Psico Social, fls. 13).

Contrastando com as ambições manifestas por parte da equipe médica paraense, os médicos de São Paulo afirmaram que João "teria que encontrar alternativas para lidar com sua sexualidade" (Relatório Bio-Psico Social, fls. 16) e sublinharam a imprescindibilidade do tratamento psicológico. Para essa equipe, seria pouco provável que João tivesse filhos, já que não teria ereção nem ejaculação. Apoiando a cirurgia de pretensões mais modestas, a assistente social que acompanhava o menino e sua mãe em São Paulo expressou sua opinião nos seguintes termos: "ainda mais traumático seria conviver sem o órgão, principalmente no contato com outros garotos" (Relatório Bio-Psico Social, fls. 14).

Apesar da viagem e da aparente conformidade entre as expectativas dos médicos de São Paulo e da assistente social que acompanhava a vítima e sua família, a cirurgia não foi realizada. Durante o período de internação em São Paulo, um desconhecido apresentou-se como policial e teria comunicado à mãe da vítima que realizaria uma "sessão de hipnose" para colher informações sobre o criminoso. Solicitou que a mãe os deixasse a sós, o que ela negou e chamou a equipe médica. Após esse episódio, a Fundação do Bem Estar Social do Pará, instituição que geria a estadia do menino em São Paulo, determinou que o melhor a ser feito era viabilizar o retorno da vítima e de sua mãe para Altamira, mesmo sem a cirurgia. 
No relato da assistente social que acompanhava João na viagem a São Paulo, o incidente somou-se às cirurgias mal sucedidas anteriores, provocando na vítima um "trauma" em relação ao acompanhamento médico. Ao voltar para Altamira, João negava-se a ir ao médico, mesmo quando sentia dores não relacionadas à sua cirurgia. Meses depois, acompanhando a vítima em uma consulta, a assistente social teria surpreendido uma enfermeira chamando seus colegas para "conhecer o emasculado" que aguardava atendimento já com o roupão do hospital. Essa cena foi registrada no relatório que, entre outras coisas, demandava que os sobreviventes fossem atendidos sempre por uma mesma equipe (Relatório Bio-Psico Social, fls. 22).

Apesar das intervenções cirúrgicas terem se estendido por vários anos, os médicos defendiam que os corpos deveriam ser "reconstruídos" no menor prazo possível. Quanto mais tempo as vítimas convivessem com o corpo mutilado, mais profundo seria seu sofrimento. Quanto mais tempo vivessem sem o "pênis", mais difícil seria a "busca pela identidade masculina". O crime do qual foram vítimas teria, segundo essa visão, interrompido o processo de transformação de "meninos" em "homens". A "masculinidade" das vítimas teria sido roubada juntamente com o órgão sexual, construindo a relação de sinédoque entre pênis e masculinidade, tal como proposto por Mehta (2000). No esforço de amenizar o sofrimento das vítimas e de seus familiares, a medicina se constitui como a principal ciência: uma forma de saber-poder adequada para agir sobre aqueles corpos (Foucault, 1999), embora a psicologia não tenha sido posta ao largo deste processo.

Nesse cenário, o termo "emasculação" não poderia ter sentido mais preciso, pois ele confere sentido não apenas à dimensão da mutilação daqueles corpos, mas à perda de algo insuficientemente desenvolvido na época do crime: a "masculinidade". Os procedimentos médicos, então, visam "desemascular" os garotos. Contudo, a reconstrução física dos corpos seria sempre imperfeita: próteses não são pênis; o tecido extraído da barriga tem aparência diferente; as cicatrizes no abdome, nas nádegas e nas coxas denunciam o périplo cirúrgico. Para a tarefa 
de melhor aceitar as imperfeições e limitações da medicina, sugere-se o "acompanhamento psicológico".

Percebe-se, assim, que o corpo mutilado não deveria ser aceito pelas vítimas, mas reparado pela medicina. O que elas precisariam aceitar seriam as dores, a ansiedade $e$ as imperfeições decorrentes das intervenções cirúrgicas. A posição passiva imposta aos sobreviventes ao longo dos procedimentos cirúrgicos desconstrói-se nas expectativas sobre o acompanhamento psicológico. As vítimas teriam que conseguir, de algum modo, "manipular a identidade deteriorada" (Goffman, 1978) de sobreviventes aos crimes de "emasculação", mesmo que tivessem seus corpos reconstruídos. O consenso em torno da decisão de que os corpos deveriam ser alvo de intervenções cirúrgicas reforça a pretensão da medicina de restabelecer padrões supostamente "naturais" e "normais". Em vista desse objetivo, as angústias, o medo, o pós-operatório dolorido e a exposição na mídia foram avaliados como um mal menor em relação aos efeitos das cirurgias que recomporiam os corpos $e$ identidades "emasculadas".

\section{Reparando os crimes}

O início das investigações policiais a respeito dos "crimes de emasculação", como vimos, se deu a partir do assassinato de Jaenes, que seria a sexta vítima na contagem dos ativistas. Para a polícia, contudo, os crime de "emasculação" restringiram-se a quatro casos: as tentativas de homicídio contra João e Pedro e aos homicídios do indígena Judirley Chipaia e de Jaenes. Em todos eles, a "emasculação" era não só comprovável como publicamente conhecida. Durante o período em que os crimes ocorreram, não foram poucas as pessoas que iam ao hospital que servia de necrotério ver o corpo mutilado das vítimas, ou que, participando dos mutirões de busca, observaram o cadáver ainda na mata, como revelam os depoimentos contidos no processo judicial. 
O fato é que, para a polícia, as "emasculações" eram radicalmente diferentes dos desaparecimentos de meninos referidos pelo ativismo local como conectados aos crimes. Para um delegado entrevistado, "desaparecer" era algo corriqueiro em regiões pobres como Altamira, considerando que "os filhos saem de casa voluntariamente porque seus pais não são capazes de sustentá-los". " Para os familiares, os corpos não haviam sido encontrados justamente pelas ações ineficientes da polícia. Os sequestros são ainda menos legítimos aos olhos policiais, já que teriam como única fonte as declarações de crianças assustadas com os crimes que se repetiam no município. ${ }^{10}$

Nesse cenário, apenas cinco dos 26 casos de "emasculação" figuraram no processo judicial. Ainda assim, a estratégia dos familiares consistiu em pressionar juízes, promotores e políticos, entre outros agentes, para que o processo fosse julgado mesmo com suas falhas e omissões. A repercussão alcançada com 0 julgamento tornava o momento propício para denunciarem a falta de resposta da polícia e da justiça aos outros crimes, segundo consideravam. O julgamento, como declarou Dona Rosa Pessoa, mãe de Jaenes, "não traz a vida dos meninos de volta", mas seria um modo de "fazer a justiça valer" (Entrevista, 2009).

A fase processual não se mostrou mais simples do que as investigações policiais: ao todo, foram onze anos de espera pelo

9 A caracterização do desaparecimento como um "caso atípico", isto é, sem correspondência no Código Penal, pode ser apontada como uma das causas da percepção policial de que os desaparecimentos não são "casos de polícia", mas "problemas de família" ou mesmo "do Estado" (Ferreira, 2011 e 2013).

${ }^{10}$ Um exemplo de situação avaliada como "sequestro" e incorporada ao "caso" ocorreu com José, de 12 anos, que em 1991 voltava da escola quando um desconhecido encostou uma faca em sua cintura, ordenou que ele não reagisse e continuasse caminhando. Depois de muito andar, chegaram a uma região conhecida como "lixeira" e lá o menor foi amarrado e vendado. Antes disso, José observara uma pasta preta em cima da qual estava uma gilete e uma tesoura. Em depoimento prestado à polícia, a vítima relatou que o sujeito o teria levado para um local ainda mais distante e disse "aqui não vai dar" e então retornaram para a "lixeira". Aproveitando um momento de distração do sequestrador, o menino conseguiu se desamarrar e escapou. 
julgamento. Para os integrantes do Comitê, os acusados não eram julgados porque seriam pessoas "ricas" e "poderosas", enquanto os meninos e seus responsáveis eram pessoas "pobres" e "sem recursos". De fato, foram muitos os advogados - alguns de fora da cidade e do estado - contratados para a defesa dos acusados, que permaneceram quase todos os onze anos em liberdade, graças a habeas corpus e outras decisões judiciais.

$\mathrm{O}$ processo de criação de assimetrias por parte dos governos, segundo Tilly (1999), é dissimulado pelas políticas e bens sociais destinados aos "hierarquicamente inferiores". Nesse sentido, embora a morosidade do judiciário seja um problema com causas complexas, a acusação a cargo da justiça pública esbarra em problemas como o excesso de trabalho dos promotores, a precariedade estrutural do Ministério Público e, o que me parece ser especialmente influente no caso em análise, a alta rotatividades dos profissionais em cidades de pequeno porte como Altamira. Segundo Sadek (1999), a ascensão dos magistrados das cidades menores para as cidades maiores traz consequências como a falta de conhecimento sobre a realidade local e a percepção do ofício como uma questão excessivamente burocrática e técnica (Sadek, 1999:14). Minha observação sobre o caso dos meninos emasculados de Altamira permite acrescentar mais uma tendência perniciosa nessa estrutura: a tendência a fugir de conflitos, sobretudo quando envolvem autoridades ou pessoas com elevado poder econômico que poderiam dificultar futuras transferências para outras comarcas.

Apesar de lidarem com uma estrutura desfavorável, os familiares das vítimas estavam assistidos. Através da Igreja Católica e de várias parcerias estabelecidas por seu intermédio, o "caso" ganhou repercussão no país e fora dele. Instruídos pelos cursos de formação oferecidos pelos religiosos, os familiares estudaram seus "direitos" e puderam, em várias ocasiões, cobrar medidas e exigir os procedimentos que sabiam serem certos. Utilizando um formato de mobilização afinado aos princípios católicos, os familiares organizaram caminhadas e levavam, em seus próprios corpos, os nomes $e$ as fotografias de crianças 
mutiladas, além de carregarem cruzes, caixões, velas e flores e assim comunicavam a dor e o sofrimento de que eram duplamente vítimas: dos crimes em si e da morosidade da justiça. ${ }^{11}$ Em alguns momentos, contudo, a figura dos religiosos, especialmente do Bispo do Xingu Dom Erwin Krautler, mostravase decisiva como instrumento de pressão.

Em 1997, o Centro de Defesa da Criança e do Adolescente (CEDECA-Emaús) de Belém, na figura de sua coordenadora Celina Hamoy, prestou assessoria jurídica aos familiares das vítimas, atuando como assistente de acusação. A mobilização em torno dos crimes, a meu ver, foi fundamental para a realização do julgamento e também para uma série de outras situações que, apesar de previstas em nosso ordenamento legal, poderiam não ter sido levadas em conta, como a exumação dos corpos não periciados. A importância do ativismo em "casos" nos quais os acusados são membros da elite ou integrantes das forças armadas aparece bem descrita nos trabalhos de Araújo (2008), Catela (2001), Leite (2004) e Vianna e Farias (2011), entre outros autores. Neles também, as características mais brutais dos crimes são sublinhadas de forma a constituir a adesão daqueles que, pela primeira vez ou não, tomam conhecimento do "caso".

A ação política dos ativistas de Altamira sublinha a "emasculação" como elemento distintivo dos crimes brutais junto aos quais militavam, ainda que tal mutilação não tenha sido praticada em todos aqueles corpos. Na lógica dos familiares envolvidos em torno do Comitê, bem como de seus apoiadores, a "emasculação" comparece enquanto certeza (nos crimes em que a natureza das lesões foi observada nos corpos das vítimas, por leigos ou especialistas), possibilidade (nos desaparecimentos jamais esclarecidos) ou acontecimentos evitados nos casos em que as vítimas conseguiram fugir - classificados como "sequestros". Distantes dessa lógica, estão a polícia e a justiça, para quem "emasculados" são aqueles que tiveram o órgão sexual extirpado.

${ }^{11}$ A influência católica nos estilos de mobilização foi descrita exemplarmente por Almeida (1993) e Chaves (2000). 
Após o julgamento, uma outra reivindicação teria surgido, a responsabilização civil do Estado. Não apenas os homicídios (tentados ou consumados) seriam de responsabilidade do Estado, mas também os desaparecimentos, os sequestros e, sobretudo, sua omissão. Nas palavras da coordenadora do CEDECA:

O CEDECA começou a atuar no processo porque o Estado não dava nenhuma resposta. (...) Havia o debate se deveria discutir a ação indenizatória ou não. A busca das famílias era para responsabilização penal daqueles que a polícia dizia que eram os culpados. Naquele primeiro momento, as famílias decidiram que não, que não se devia entrar com uma ação de responsabilização civil. Então nós começamos o foco na responsabilização penal. (...) Só que chegou um momento em que as famílias começaram a ver que isso não estava dando resultado nenhum. E precisava alertar o Estado de que o seu processo de omissão teve tantas mortes como resultado e que... o Estado não assumia. Tantas mortes poderiam ser evitadas e não foram por omissão do Estado mesmo, dentro do processo de proteção daqueles meninos e meninas lá em Altamira. (...) E aí se começou esse debate... Foi então uma proposição do Comitê que nós começássemos a discutir (Entrevista, 2008, grifos meus).

Seguindo dispositivos da Comissão Interamericana de Direitos Humanos, durante a década de 90, vários países da América Latina passaram a estipular medidas "reparativas" para as consideradas vítimas da repressão política dos governos autoritários dos anos 70 (Tello, 2003). No Brasil, pela Lei 9140/95, ficou previsto pagamento de indenização para os cônjuges, companheiro ou companheira, descendente, ascendente e, em último caso, aos parentes colaterais de pessoas que desapareceram ou sofreram outras violações de direitos durante a "repressão política".

Fora do contexto sul-americano, as Comissões de Verdade e Reconciliação na África do Sul recomendaram que as vítimas do Apartheid fossem financeiramente recompensadas (Buford e Van Der Merwe, 2004). Antes dessa recomendação, um conjunto de 
vítimas já havia recebido a indenização denominada "Urgent Interin Reparation", pois a Comissão de Verdade entendeu que elas não sobreviveriam sem imediato atendimento "médico, emocional, educacional, material e simbólico" (Buford e Van Der Merwe, 2004). Segundo os autores, as Comissões de Verdade e Reconciliação sul-africanas são consideradas "políticas de reabilitação e reconciliação abrangentes e eficazes", não apenas pela indenização promovida, mas pela retirada das atrocidades do domínio do silêncio (Buford e Van Der Merwe, 2004:71). De acordo com os autores, leis internacionais humanitárias, como a publicada pela Anistia Internacional em 2003, afirmam que reparação é um direito $e$, mais do que isso, uma obrigação quando o Estado é responsável ou co-responsável pela violação de direitos humanos.

A indenização financeira enquanto uma forma possível de "reparar um dano" é parte do processo mais amplo articulado à concessão de pensões aos sobreviventes João e Pedro. A demanda do Comitê e de seus apoiadores era a de que os familiares de todas as vítimas do "caso" (incluindo desaparecidos $e$ sequestrados) recebessem as indenizações, além dos sobreviventes. As negociações com os governos do Pará, contudo, não se mostraram muito fáceis. Em 2005, mais de quinze anos depois do crime que sofreram, o então governador Simão Jatene (PSDB) concedeu através de lei regulamentar a "pensão especial" em favor dos sobreviventes. Referidos como "vítimas do episódio conhecido como 'Meninos Emasculados de Altamira'" eles passaram a receber mensalmente a quantia de quinhentos e vinte reais. $\mathrm{O}$ artigo segundo da lei que aprovou a pensão dos sobreviventes define o pagamento como "indenização por responsabilidade civil".

Em Altamira, a concessão de pensões para João e Pedro é o primeiro caso do gênero. Já no âmbito do Pará, recebem pensões indenizatórias vítimas do chamado "massacre de Eldorado dos 
Carajás" e a "menina de Abaetetuba", entre outros. ${ }^{12}$ A prioridade aos meninos que sobreviveram às emasculações foi produto de negociações internas ao próprio Comitê, o que se justificaria, aos olhos dos envolvidos, pela dificuldade de encontrarem emprego $e$ pelos gastos com saúde - lembrando o sentido da "urgência" da reparação sul-africana vista acima. Em 2008, na gestão da governadora Ana Júlia Carepa (PT), a Assembleia Legislativa aprovou lei extraordinária que concede pensão a nove familiares de vítimas, não mais aquelas cuja "emasculação" era comprovável, mas aqueles que estiveram na "luta" durante quase vinte anos.

A propaganda oficial do governo de Ana Júlia apresentava as indenizações como um caminho rumo à "justiça social" e seria ainda uma forma de o Estado reconhecer sua "parcela de responsabilidade". A punição, portanto, incide sobre algo que segundo Foucault (1997), estaria na base fundacional de seus poderes que é o "deixar morrer". No entanto, o que as indenizações parecem indenizar é menos um conjunto possível de gastos e mais uma situação de sofrimento classificada como irreparável.

Os familiares argumentam que os sobreviventes teriam prioridade no recebimento das indenizações por terem "gastos" com sua saúde, mas também sublinham o fato deles serem as "vítimas que mais sofreram". Enquanto os familiares se veem como merecedores da pensão por terem passado a vida "sentados em uma cadeira de Tribunal" e constrangidos pelo compromisso de "contar para uma multidão, de cinco em cinco dias, o acontecido", os sobreviventes, além desses mesmos

\footnotetext{
${ }^{12}$ Em abril de 1996, no Estado do Pará, 19 trabalhadores conhecidos como "sem terra" foram mortos em um confronto com policiais militares. Outros tantos ficaram feridos. Em 2007, uma menina de 15 anos foi encarcerada junto com vinte homens em uma cela da delegacia na cidade de Abaetetuba (PA), cidade $100 \mathrm{~km}$ distante da capital. Segundo o CEDECA, que também prestou assistência jurídica nesse caso, a menina teria sido vítima de estupro, atentado violento ao pudor, lesões corporais, escassez de alimentos e produtos de higiene durante os 30 dias em que ficou presa.
} 
326 Recompondo corpos, reconstruindo trajetórias

compromissos, convivem com as marcas da violência e da desassistência em seus corpos. ${ }^{13}$

\section{Perspectivas finais}

Em maio de 2009, fui a Altamira pela primeira vez. Previamente, havia combinado com Dona Rosa Pessoa, mãe de Jaenes e então coordenadora do Comitê, um encontro com ela e com os outros familiares. Somente quando cheguei à cidade manifestei meu interesse em entrevistá-los, frequentar suas casas e conhecer um pouco mais de sua "luta". Antes da reunião em que fui oficialmente apresentada ao grupo, participei de uma manifestação pelo Dia Nacional de Combate ao Abuso e à Exploração Sexual de Crianças e Adolescentes. Nesse dia, conheci Ester, irmã de Klebson, morto e "emasculado" aos 12 anos de idade. No grupo em que estávamos eu, Dona Rosa, Ester e mais duas mães de vítimas, Ester comentava a prisão de um dos condenados no "caso dos meninos", que estava foragido. Como ironia e revolta, Ester afirmou que, em sua opinião, "não era ele que estava foragido da justiça, mas a justiça que se foragia dele e do povo".

A revolta e a indignação eram marcas não apenas da fala de Ester, mas também de outros familiares, tanto em nossas entrevistas, quanto nos eventos públicos os quais tive oportunidade de presenciar. Anos passados desde os crimes, desde o julgamento e até mesmo desde a concessão das indenizações, a indignação estava ali e tinha um direcionamento claro: às "autoridades". Klebson, o irmão de Ester, foi vitimado um mês depois do crime contra Jaenes, quando a equipe da

\footnotetext{
${ }^{13}$ A fala de Dona Carolina, mãe de Maurício, desaparecido aos 14 anos, é a inspiração desse trecho: "Ah, Carolina tá ganhando um salário'. Eu digo: 'um salário não paga uma sentada nossa numa cadeira daquela do Tribunal'. Por causa do sofrimento que causou a nós. Sabe o que é, mana, você perder um filho que era um pedaço de você e você ter que de cinco em cinco dias, de oito em oito dias ter que sentar na frente de uma multidão e contar praquelas pessoas tudo o que aconteceu?!" (Entrevista com Dona Carolina, 2010).
} 
Polícia Civil enviada especialmente para investigar o "caso" estava na cidade. Ainda assim, o delegado recusou-se a acolher a comunicação de desaparecimento feita por Ester e sua mãe. Ele teria alegado que o desaparecimento era forjado, já que elas não possuíam certidão de nascimento que pudesse comprovar a existência do menino. Dias depois, quando o corpo foi encontrado, o "caso" de Klebson passou a ser investigado pelo delegado e acabou tendo um peso decisivo no primeiro indiciamento.

$\mathrm{Na}$ visão da promotora de justiça que recebeu o inquérito, contudo, o homicídio qualificado de Klebson não era do mesmo tipo dos demais crimes. Apesar de "emasculado", a natureza de sua lesão era outra: as "bordas irregulares" mostrariam que a genitália havia sido "arrancada", o que diferia dos demais casos, nos quais ela fora "extirpada com precisão cirúrgica" (Processo, fls. 183). O crime contra Klebson, visto como até mais brutal que os demais (a vítima foi ainda escalpelada e eviscerada), foi utilizado como mostra do "poder" e da "brutalidade" dos "poderosos locais". Paradoxalmente, não mobilizou esforços na descoberta desse outro algoz.

A partir dessas últimas observações sobre o "caso", restam dois argumentos acerca da centralidade da "emasculação". O primeiro deles é o risco assumido na caracterização dos crimes como acontecimentos únicos, distintos de toda a violência praticada na região, produto da ação seja de uma personalidade desviante, seja de um grupo de pessoas ligadas por motivos espúrios (como a participação em "rituais satânicos"). Representar os crimes dessa forma implicou em adesão significativa, como argumentei, mas parece ter mistificado aqueles que seriam "os criminosos". Imaginava-se que seriam pessoas de fora de Altamira, ligadas aos mais importantes políticos. Durante um tempo, acreditou-se que os órgãos sexuais seriam levados aos Estados Unidos para implante em outros corpos. ${ }^{14}$ Quando foi

${ }^{14}$ Discutindo sobre pobreza e estilos de vida no interior do nordeste brasileiro, Scheper-Huges (1992) descreve o constante temor de seus interlocutores de que suas crianças fossem sequestradas, tendo em vista os rumores de que crianças 
aventada a possibilidade de os crimes estarem relacionados a uma "seita satânica", dizia-se que ela teria células em vários países. Nenhuma dessas relações foi comprovada. Os "rumores", em torno do caso em seu potencial performativo tornaram-se capazes de transformar o "meu medo do outro" em "o outro é amedrontador" (Das, 2007:134). No caso, esse "outro amedrontador" materializa-se nas figuras de "poderosos" tais como comerciantes, fazendeiros, médicos e políticos.

Por fim, politizar os crimes tendo a "emasculação" como síntese da violência implicou no confronto ao potencial mais desonroso que ela apresentava. A vida dos meninos foi interrompida não de qualquer maneira, mas em seus corpos foi impressa uma marca brutal, desumana, comum aos animais: a castração. Os familiares das vítimas superaram o que poderíamos chamar de ponto mais denso da humilhação ao levarem a público o "caso", ao contarem "de cinco em cinco dias" todo o acontecido. Mas isso, naturalmente, não esteve livre de um custo adicional. Como argumentam teóricas feministas, entre as quais Mason (2002), toda violência física é também uma agressão moral, que humilha $e$ injuria. ${ }^{15}$ Não por acaso, a expressão "emasculados", na fala dos familiares das vítimas, é restrita a eventos não cotidianos, nos quais subentende-se que o "caso" não seja conhecido de todos. No âmbito mais restrito da ação política, ou entre conhecidos, o "caso" é referido como sendo o "dos meninos".

pobres eram sequestradas para extração de órgãos. Quando perguntados sobre a identidade desses "ladrões", os interlocutores respondiam serem "os grandes" ou "os politicos" (Scheper-Huges, 1992:236). Na interpretação da autora, tal temor teria suas raízes no distanciamento em relação aos procedimentos médicos e na distância social existente entre "pobres" e "ricos", sintetizada na frase "os ricos estão nos comendo" ou "os ricos estão comendo nossas crianças" (ScheperHuges, 1992:236).

${ }^{15}$ A humilhação como estratégia de desestruturação moral foi também analisada por Diniz (2001), escrevendo sobre a universalidade dos direitos humanos. Em sua análise, a autora recorre a Rorty (1997) para conferir à humilhação o status de dor moral, sentido bastante próximo ao utilizado pelos meus interlocutores. 


\section{Referências bibliográficas}

AlmeidA, A. W. Conflito e Mediação: os antagonismos sociais na Amazônia segundo os movimentos camponeses, as instituições religiosas e o Estado. Tese de Doutorado, Programa de PósGraduação em Antropologia Social, UFRJ, 1993.

ARAÚJO, F. "Falta alguém na minha casa": desaparecimento, luto, materinidade e política. In.: KANT DE LIMA, R. (Org.) Antropologia e Direitos Humanos 5. Brasília e Rio de Janeiro, ABA, Booklink, 2008, pp.166-225.

. Das consequências da "arte" macabra de fazer desaparecer corpos: violência, sofrimento e política entre familiares das vítimas de desaparecimento forçado. Tese de Doutorado, Programa de PósGraduação em Antropologia e Sociologia, UFRJ, 2012.

Buford, W. e VAN DER MERWE, H. Reparation In Southern Africa. Cahiers D'études Africaines, vol. 44, issues 1-2, 2004. [<http://www.Csvr.Org.Za/Wits/Papers/Papwbhv.Htm - acesso em: outubro de 2012].

CAETANo, D. A verdadeira história do caso Evandro. São Paulo, Naós, 2010.

CARdoso, F. H.; Muller, G. Amazônia - Expansão do Capitalismo. São Paulo, Brasiliense, 1977.

CATEla, L. Situação-limite e Memória: a reconstrução do mundo dos familiares de desaparecidos na Argentina. São Paulo, Hucitec-Anpocs, 2001.

CHAVES, C. A marcha nacional dos sem-terra: um estudo sobre a fabricação do social. Rio de Janeiro, Relume-Dumará, 2000.

COMEFORD, J. Fazendo a luta: sociabilidades, falas e rituais na construção de organizações camponesas. Rio de Janeiro, Relume-Dumará, 1999.

DAS, V. Life and Words: violence and the descent into the ordinary. Berkeley, University of California Press, 2007.

DINIZ, D. Antropologia e os limites dos Direitos Humanos: o dilema moral de Tashi. In: NovAES, R.; KANT DE LimA, R. (Orgs.) Antropologia e Direitos Humanos. Prêmio Associação Brasileira de Antropologia, Fundação Ford. Niterói, Eduff, 2001, pp.17-46. 
Douglas, M. Pureza e Perigo. São Paulo, Perspectiva, 1976.

Fausto-Sterling, A. Sexing the Body: Gender Politcs and the Construction of Sexuality. New York, Basic Books, 2000.

FERREIRA, L. Uma etnografia para muitas ausências: o desaparecimento de pessoas como ocorrência policial e problema social. Tese de Doutorado. Programa de Pós-Graduação em Antropologia Social, UFRJ, 2011.

- O desaparecimento de pessoas no Brasil contemporâneo: a ausência de pessoas como matéria-prima de um problema social. In: VIANNA, A. (Org). O fazer e o desfazer dos direitos: experiências etnográficas sobre política, administração e moralidades. Rio de Janeiro, E-Papers, 2013, pp.36-67.

Foucault, M. História da Sexualidade I: a vontade de saber. Rio de Janeiro, Graal, 1999.

. Em Defesa da Sociedade: curso no Collège de France (19751976). São Paulo, Martins Fontes, 2002a.

. Os Anormais: curso no Collège de France (1974-1975). São Paulo, Martins Fontes, 2002b.

GOFFMAN, E. Estigma: notas sobre a manipulação da identidade deteriorada. Rio de Janeiro, Zahar, 1978.

LAQUEUR, T. Making Sex: Body and Gender fron the Greeks to Freud. Cambridge/London, Harvard University Press, 1990.

LATOUR, B.; WoOlgar, S. A vida de laboratório: a produção dos fatos científicos. Rio de Janeiro, Relume-Dumará, 1997.

LeITE, M. As mães em movimento. In.: LeITE, M; BIRMAN, P. (Orgs). Um mural para a dor: movimentos cívico-religiosos por justiça e paz. Porto Alegre: Editora da UFRGS, 2004, pp.141-190.

MACHADO, P. O sexo dos anjos: um olhar sobre a anatomia e a produção do sexo (como se fosse) natural. Cadernos Pagu (24), Campinas-SP, Núcleo de Estudos de Gênero-Pagu/Unicamp, 2005, pp.249-281.

MASON, G. The Spetacle of Violence: homophobia, gender and knowledge. London and New York, Routledge, 2002. 
MEHTA, D. Circumcision, Body, Masculinity: the ritual wound and collective violence. In.: DAS, V. et alli (Eds). Violence and Subjectivity. Berkeley, Los Angeles, London, University of California Press, 2000, pp.79-101.

RORTY, R. On Ethnocentrism: a reply to Clifford Geertz. In: Objetivity, Relativism and Truth. Cambridge, Cambridge University Press, 1997.

SADEK, M. T. O Sistema de Justiça. In: SADEK, T. O Sistema de Justiça. São Paulo, Idesp, Sumaré, 1999, pp.7-18.

SCHEPER-HugheS, N. Death without weeping. The violence of every day life in Brazil. Berkeley, Los Angeles, Oxford, University of California Press, 1992.

SEYFERTH, G. Imigração e Cultura no Brasil. Brasília, Editora da Universidade de Brasília, 1990.

TAVARES, V. Colonização Dirigida no Brasil: suas possibilidades na região Amazônica. Rio de Janeiro, Instituto de Planejamento Econômico e Social, 1972.

TELLO, E. La fuerza de la cosa dada: derechos humanos, política y moral en las 'indemnizaciones' a las víctimas del Terrorismo de Estado en Argentina. In.: NOVAES, R.; KANT DE LIMA, R. (Orgs.). Antropologia e Direitos Humanos, vol. 2, Niterói, RJ, Eduff, 2003, pp.37-74.

TILLY, C. Durable Inequality. Berkeley, Berkeley University Press, 1999.

VelHo, O. G. Frentes de expansão e estrutura agrária: estudo do processo de penetração numa área da Transamazônica. Rio de Janeiro, Zahar Editores, 1981.

VIANNA, A.; FARIAS, J. A guerra das mães: dor e política em situações de violência institucional. Cadernos Pagu (37), Campinas-SP, Núcleo de Estudos de Gênero-Pagu/Unicamp, 2011, pp.79-116.

WeBER, M. Economía y Sociedad: esbozo de sociología comprensiva. México, Fondo de la Cultura Económica, 1974. 